\title{
English Language Teaching at Expenses of Thai Language Teaching for Urban Refugee Language Learners in Thailand: Social Inequalities Related to What Languages to Teach
}

\author{
Hugo Yu-Hsiu Lee \\ National Institute of Development Administration (NIDA), Bangkok, Thailand \\ Email: YL15@umail.iu.edu
}

\begin{abstract}
This inquiry on young refugee language learners presents findings that have been yielded from an empirical study and conducted over a period of 8 months in Thailand. This study took an angle in multidisciplinary fields of language teaching by examining socio-economic inequalities occurred to urban refugee children and adolescents resulted from their formal schooling interruption as closely in relation to what languages are taught in their humanitarian based language learning programs. A central argument throughout this paper has been balancing languages to teach for these young language learners by refocusing attentions on teaching needed Thai language that helps formal schooling interrupted refugee children and adolescents to resume their study in local Thai schools, accompanied by teaching globally-oriented English language. By the same token, while the promise of English language teaching and learning might empower young urban refugee students, English language teaching cannot be at expenses of Thai language teaching because the latter is urgently needed for these young urban refugees to continue their formal schooling and decreases inequalities.
\end{abstract}

Index Terms -English language teaching, Thai language teaching, urban refugee language learners

\section{INTRODUCTION}

In discussing relationship between foreign/second language teaching and inequalities in societies resulted from formal schooling interruption, the needs of what languages to teach for marginalized minority groups such as young urban refugee students are frequently overlooked. A real example is given as follows: Teaching English language is commonly seen as a crucial resource for English as foreign/second language learners to access power, prestige, status, and socio-economic mobility. However, challenging traditional notions of teaching a powerful language such as English to decrease social inequalities, data obtained from urban refugee language learners in Thailand show otherwise. On condition that these young refugee language learners continue to study in English language programs provided by refugee shelters, they are in a disadvantaged position to not acquire needed Thai language competencies from their heterogeneous and linguistically diverse refugee peers and refugee English teachers, and are therefore unable to enroll in local Thai schools. Receiving English language education among these young urban refugees is at expenses of learning immediately needed Thai language to terminate their formal schooling interruption.

One of the causes of inequalities is access to schooling. As evidenced by data in this study, acknowledged factors that impact socio-economic inequality include formal schooling interruption among urban refugee children and adolescents. Often socio-economic inequalities between mainstream groups and minority refugee communities can partially be caused by continuation of formal schooling with the former and continuation of formal schooling interruption with the latter. Ideally, formal schooling interrupted refugee children and adolescents should be entitled with Thai language courses as preparation to enroll in local Thai schools. Humanitarian based language programs designed for urban refugee children and adolescents organized by nongovernment groups, nonetheless, fail to offer regular Thai language courses in preparing young refugee students with Thai language proficiencies needed to continue their formal schooling in Thailand. When English language teaching and Thai language teaching as two competing orientations in language teaching markets, English language teaching often foregrounds Thai language teaching in humanitarian based language learning programs, resulted from administrative decisions as well as urban refugee language learners' choices. Prioritizing English language teaching accompanied with discouraging Thai language teaching increases socioeconomic inequalities for urban refugee children and adolescents from their Thai counterparts. To close this gap, this study suggests that beliefs and/or ideologies that promote English language teaching only should be contested. Moreover, Thai as a second language courses are recommended for formal schooling interrupted urban refugee students to enable them in resuming formal schooling in Thailand, ultimately shortening their socio-economic inequalities from their Thai counterparts. 


\section{BACKGROUND REVIEW}

\section{A. Refugees and Asylum Seekers Resettle in Urban Areas of Thailand}

In the world we are living today approximately eleven million people are displaced at a domestic level and transnational level(UNHCR, 2006). Suffering, hardship, misery, torment and adverse economy resulted from internal political unrest such as civil wars are evident especially when their victims come to live in our neighborhoods as refugees. More often than not wars generate enormous death tolls, disrupt accumulation of physical capitals and properties, and erode freedom in civil levels. Transnational migration occurs when these horrors displace population from their home countries to resettle in a new country. For the reason that civil conflicts, political, and religious persecutions by and large go on for many years, these forced migrants have been frequent and on the rise in numerous countries of the world. Those seeking asylum hope for refugee status being granted and individuals "owing to a wellfounded fear of being persecuted for reasons of race, religion, nationality, membership of a particular social group or political opinion, is outside the country of his/her nationality and is unable or, owing to such fear is unwilling, to avail himself of the protection of that country" are categorized as refugees by the United Nations (Huguet \& Punpuing, 2005)

Many countries have acknowledged an ethical responsibility to admit refugees and rendered humanitarian assistance to these extremely vulnerable persons. The Kingdom of Thailand is one of the largest shelters in the world for displaced people, refugees and asylum seekers. Millions of displaced people flee their homelands to escape war, long-term economic struggle, political or religious persecution, and violence by military to settle in Thailand (Huguet \& Punpuing, 2005). Some asylum seekers from different countries come to Thailand and take residence in urban areas, because it has comparatively easy-to-meet visa requirements than other countries (Jesuit Refugee Service, n.d, online). Most of them come from countries of Afghanistan, Congo, Mainland China, Nepal, North Korea, Pakistan, Sri Lanka and Vietnam. Sociolinguistically transnational refugee resettlements should be seen as a life-long process. Exploring needs in language teaching and learning among urban refugees is essentially a moral imperative to help them resettle in Thailand

\section{B. Issues of Language Teaching in Humanitarian Based Language Learning Programs in Thailand}

Despite Thailand is a prominent receiving country for refugees and asylum seekers in almost worldwide migration and resettlement, yet there is increasingly a huge gap between humanitarian based language learning programs in Thailand and actual language needs among refugees. Data in this study show that these language learning programs at urban refugee shelters are at risk to create enormously large social inequality for urban refugee children and adolescents from their Thai counterparts, because of languages they do not offer to teach. On the one hand, formal schooling interrupted refugee children and adolescents do not receive regular Thai language assistance, but they are entitled to enroll in a local Thai school nearby their residence. As a result, they continue their formal schooling interruption and are thus not ready to enroll in local Thai schools. On the other hand, the extreme focus on English language teaching in a number of urban refugee language learning programs skips the immediate need for young refugee students to learn Thai language. To make the matter worse, English language teaching focused programs designed for young urban refugee students fail to provide a comprehensive curriculum with balanced developments in different subject matters suited for refugee children and adolescents in primary and secondary levels. In any case teaching English language alone cannot possibly make up refugee children' and adolescents' needs in learning other subjects, i.e., mathematics, science and social studies.

\section{The Call to Teach Thai Language Regularly for Urban Refugee Children and Adolescents in Thailand}

Despite the fact that learning English language has become a critical resource of gaining power, prestige, status, and socio-economic mobility in this age of globalization, we cannot rule out the need to teach a local language for urban refugees in countries where they resettle. Only when refugees become functionally communicative in Thai language do they begin to enjoy the rewards of living in this beautiful kingdom of Thailand. Data from this present inquiry show that learning Thai language can surely help urban refugees satisfy their fundamental needs and empower their self-esteem. Mastery of Thai language can help individual and communal refugees to successfully integrate into the mainstream Thai society while waiting for a third country to adopt them. There is emerging evidence from data in this current study to show that the attainment of any medium of wider communication, a nature language acquisition to its native speakers, turns out to be a huge task for transnational refugees if they do not receive any language education to learn common media of communication in their resettled countries. The lack of mastery over a common language is widely perceived as a frustrating limitation faced by cross-national refugees trying to adapt to a new environment. Learning a second language as medium of wider communication in a host country added life difficulties to these urban refugees. Ideally, language teaching programs provided for unwilling migrants should cater to meet their different needs in language and communication. These needs of language and communication might vary significantly from those other immigrants who are willing to move to Thailand. Despite occasional Thai language training courses are provided, in Thailand rarely do humanitarian based language learning programs consider urban refugee children's needs to learn Thai language in a regular Thai language program for 1-2 years before they are competent to enroll in nearby Thai schools.

Exploring research perspectives that frame the issue of language teaching for formal schooling interrupted refugee children and adolescents in Thailand, literature evidently show a positive effect on transnational refugees who receive second language education before they are placed in mainstream classrooms in a host country. Australia (Settlement 
English, n.d.), Canada (Adelman, 1990) and USA (Ellis, 2010), for example, prepare refugee children and adolescents with needed English as second language courses in enabling them to continue their formal schooling in their resettled English speaking countries. Nevertheless, data from this inquiry show that Thailand has produced little evidence of improvement in these humanitarian based language learning programs to help urban refugee children and adolescents learn Thai language regularly.

\section{Methodology}

To develop an understanding regarding contextualized factors that lead to the emergence of English language teaching at costs of Thai language teaching for formal schooling interrupted refugee children and adolescents in urban areas of Thailand, this study pursues the following research question in this contribution: what are contextualized factors that shape and influence foreign/second language learning among formal schooling interrupted urban refugee children and adolescents in Thailand and how can we do to meet their needs of different languages through language teaching.

\section{A. Urban Refugee Sites and Young Refugee Language Learners in Thailand}

Two main types of refugees and asylum seekers currently resettle in Thailand-urban refugees and camp-based refugees. The scope of this inquiry has been limited to understand urban refugee children and adolescents particularly in regard to their language learning experiences at humanitarian based language learning programs and what languages taught in these programs are in relation to social inequalities created by extension of their formal schooling interruption.

Multiple urban refugee research sites across Thailand are characterized that in English language courses, young children focused English programs seem to coexist comfortably with adult refugee English teachers and some American volunteers. This study delved into 80 young refugee students' encounters with language needs to resume their formal schooling and what languages are taught in their humanitarian based language learning programs. Informants' age are ranged from 6-7 years old to 18-19 years old. Nuanced understanding of language teaching and learning have been expanded and modified by interview and questionnaire responses, and observation notes from these young refugee language learners in urban shelters. Adult urban refugees volunteer to teach young students in their language learning centers. Their language learning classrooms are where linguistically and culturally diverse urban refugee children and adolescents are taught in English language isolated from daily activities of neighboring Thai speaking residents. These English language education for urban refugee children and adolescents are also instructional settings where young refugee students learn to be competent members to please refugee English teachers. These urban refugee children' and adolescents' learning takes place in classroom language domains that are in particular socio-cultural and linguistic groups.

\section{B. Data Collection and Analysis}

Through interviews, observations and questionnaires, this paper disclosed what languages to teach and what languages are needed for urban refugee children and adolescents to end their formal schooling interruption in Thailand. The researcher carefully triangulates data collected from individual interviews, group interviews, follow-up interviews, participant observations, non-participant observations, and responses from questionnaires.

\section{RESULTS AND DISCUSSION}

Three main contextualized factors that depicted a young urban refugee population characterized by a multifaceted set of English language teaching and learning are examined in details. First, data indicate a strong desire to learn English among young refugee students. Not surprisingly, data reveal that almost all urban refugee children and adolescents $(98 \%, \mathrm{~N}=80)$ see a need to learn English language over Thai language. The powerful role of English language is influencing and shaping what are possibilities remained for languages other than English to teach in urban refugee settings in Thailand. Data point out that some urban refugee children and adolescents $(60 \%, \mathrm{~N}=80)$ do not see a need to learn Thai language, because they do not want to enroll in a local Thai school but wait for a third country to adopt them. However, this paper argues that lack of Thai language speaking proficiencies among these refugee children and adolescents might put them in a disadvantaged position to prolong their length of formal schooling interruption. Data report estimated 3-4 years in average of formal schooling interruption for English language learning focused participants. By marked contrast, urban refugee children and adolescents $(30 \%, \mathrm{~N}=80)$ who intend to enroll in local Thai schools see a need to learn Thai language. Data report estimated 1.5-2 years in average of formal schooling interruption for Thai language learning focused refugee children and adolescents. However, there are unfortunately no regular Thai language teaching programs provided for these urban refugee children and adolescents who need to enroll in local Thai schools and terminate their formal schooling interruption, because Thai language learning programs are only provided periodically or occasionally as non-formal language education for adult learners.

Note that different language learning programs at urban refugee shelters across Thailand are differing in their size of student body and teaching staffs, geographical locations in the Kingdom of Thailand, and available language teaching and learning resources. Thus, data gathered in this present inquiry reported in this paper cannot be generalized and/or 
applicable to every language learning programs at urban refugee shelters across Thailand. Data presented below in table 1 and figure 1 are merely estimated numbers on the basis of accessibility of limited data.

TABLE 1:

RESPONSES OF INFORMANTS WHEN ASKED WHAT AFFECTS THEM TO LEARN FOREIGN/SECOND LANGUAGES

\begin{tabular}{lcc}
\hline Contextualized factors & \# of responses from 80 informants & $\%$ of responses from 80 informants \\
\hline Seeing a need to learn English language & 78 & $>90 \%$ \\
$\begin{array}{l}\text { Heterogeneous and linguistically diverse } \\
\text { refugees see a need to use }\end{array}$ & 60 & $75 \%$ \\
$\begin{array}{l}\text { English language as a common medium of } \\
\text { communication }\end{array}$ & 20 & $25 \%$ \\
Thai friends and Thai neighbors live close & & \\
to refugee's residence & & \\
Media: Newspapers, magazines, TV, and \\
radio
\end{tabular}

Note: informants can choose more than one contextualized factors.

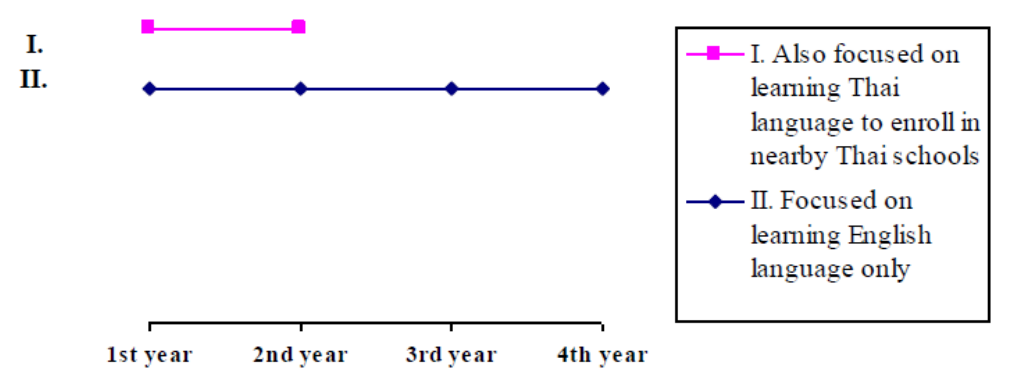

Figure 1: Relations between Foreign/Second Language Learning Choices and Time Length of Formal Schooling Interruption

i. Young urban refugee language learners see a need to learn Thai language and intend to enroll in Thai schools nearby their residence: Estimated 1.5-2 years of formal schooling interruption

ii. Young urban refugee language learners keep staying in English language learning programs and do not see a need to learn Thai language: Estimated 3-4 years of formal schooling interruption

Continued finding reports in this study, secondly, data show a need to use English language as a common medium of communication among heterogeneous and linguistically diverse refugees from Pakistan, Sri Lankan, Congo, and other countries. Even if urban refugees settle in a predominantly Thai language environment, their shelters and service centers except household language domains may not reflect the fact that the medium of communication is in Thai oral discourse. The data speak to the fact that heterogeneous and linguistically diverse urban refugees converse to each other in English language as a common medium of communication and as a medium of instruction in language learning programs. This contrast is dramatically lost in rural refugee camps, especially those who live with homogenous Burmese peers. In contrast to rural refugees who maintain their native languages within their homogeneous camps, urban refugees stated that heterogeneous and linguistically diverse peers have more effect on their increasingly use of English language as a common medium of communication when they cannot understand each others' native languages. Furthermore, data from this study contribute to current understandings of foreign/second language teaching in the context of transnational urban refugee communities by arguing that urban refugee children' and adolescents' desires to learn English language over Thai language are partially resulted from English language learning programs available and free to them. Data speak to a fact that learning English language or Thai language could be highly specific to refugee's language learning programs accessible to them. However, this study cannot go beyond its data to infer what expected outcomes are when Thai language learning programs are regular, available and free to urban refugee children and adolescents.

Third, the analysis shows that an immediate language contact with a predominant Thai language domain in Thailand has little effect or almost no effect on shaping everyday practices of English language among urban refugee communities. The Royal Thai Government did not sign 1951 Refugee Convention, so it does not have laws and permanent systems to decide whether a person is a refugee (see legal services in Bangkok Refugee Center, online). Moreover, the 1979 Immigration Act states that illegal immigrants, i.e., those without a passport, a valid visa to stay, and a work permit to get employed in Thailand, are subject to arrest, detention and deportation. Thus, urban refugees are struggling and in desperate need, seeking out a life in a hostile environment as they are not recognized as refugees by the Royal Thai government. As illegal aliens, they confront abuse, exploitation, hostility, language difficulties, prejudice, threats, and confusing legal status, and hence are subject to arrest, detention, deportation and human 
warehousing. Limited or no speaking proficiency in Thai language is dependent on the frequency of language contacts with linguistically diverse refugee peers as well as outside speakers of the predominant Thai language. Within a predominantly Thai language environment, informants assert that their less frequent language contacts with Thai language speakers outside their refugee shelters may have, nonetheless, negative effect on their Thai language learning. Note that Thai administrators and Thai social workers communicate with urban refugees in English language. For security reasons, the data reported here are evident that most urban refugees have less language contacts with outside Thai native speakers unless absolutely necessary. Although Thai government allows non-government religious organizations in collaboration with United Nations High Commissioner for Refugees (UNHCR) to provide shelters for illegal immigrants such as refugees and asylum seekers, Thai polices can arbitrarily arrest them and ask for bribes. Because some urban refugees rely on non-profit organizations and humanitarian assistance for their food supply, they might not see a need to learn Thai language to make a living in Thailand. However, other urban refugees who need to make a living in Thailand have fairly more frequencies of language contacts with Thai language speakers. It is very unfortunate but true that relatively isolated language socialization within diverse linguistic refugee communities greatly hinder urban refugee children and adolescents from acquiring needed Thai language proficiencies to continue their formal schooling in local Thai schools. To assume that young urban refugee children can be placed into mainstream Thai speaking schools without preparations in their Thai language competencies and proficiencies is beyond the scope of this current inquiry.

In combination with above three contextualized factors that affect teaching and learning of foreign/second languages among urban refugees in Thailand - a strong desire to learn English among young refugee students, a need to use English language as a common medium of communication among heterogeneous and linguistically diverse refugees, and an immediate language contact with a predominant Thai language domain in Thailand has little effect or almost no effect on shaping everyday practices of English language among urban refugee communities, now this paper shifts its attention to emphasize some findings. Challenging traditional notions of acquiring a foreign/second language of immediate medium of wider communication in a host country, the data from this current study prove that the predominantly Thai language domain plays a minimal role having little effect on the most dominant English language learning occurred among urban refugee children and adolescents in Thailand. In other words, most informants assert that they do not see an immediate need to acquire Thai language despite its demands, but data speak directly to the fact that they see a desperate need to learn English oral and written discourse. Data from this study propose to shift our perspective from viewing foreign/second language teaching as a focus on an immediate medium of wider communication, i.e., Thai language, for urban refugees to acquiring a globally-oriented foreign/second language, i.e., English language, in a resettled host country, i.e., Thailand. Note that practices of language teaching and learning reported from data in this present inquiry can only be limited to speak the fact for local contexts of some urban refuge shelters in Thailand. They do not meant to be generalize-able for other individuals and groups with similar exiled backgrounds in different contexts.

\section{CONCLUDING REMARKS AND RECOMMENDATIONS}

This present inquiry concludes with the following analysis: What has held back these humanitarian based language learning programs to prepare urban refugee students ready for resuming and continuing their formal schooling is that with extremely focus on teaching English language only, there has not been an accompanying regular Thai language program to teach Thai language.

Qualitative records from this paper add to our current understandings of young urban refugee's language learning issues and how they are in relation to formal schooling interrupted problems among them in Thailand. This paper urges that Thai as a second language programs should be established by UNHCR in meeting the needs of formal schooling interrupted urban refugee children and adolescents to continue their formal schooling in Thailand. English language only curriculum and English language focused programs accessible to refugee children and adolescents could be problematic, because English language courses alone cannot cover what urban refugee children and adolescents need in other subject areas and skills. Just because these urban refugee children $(>90 \%, \mathrm{~N}=80)$ express a strong desire to only learn English language does not mean that they do not need to develop other knowledge and skills from a variety of subject contents. These urban refugee children and adolescents are too young to make their own decisions on whether they should be only entitled to learn English language alone or they should be entitled also to learn subjects, especially Thai language, other than English language in helping them end formal schooling interruption. These educational language policy decisions should be given to UNHCR and grass-root religious groups who organize urban refugee services to make. Thus, implications of this study are geared for language policy makers, literacy planners, language educators, foreign/second language teachers and anyone interested in meeting the needs of language, communication and formal schooling continuation for urban refugee children and adolescents. With decreasing social inequality in mind, this article is intended to bring together scholars from a variety of disciplines, graduate students, social workers and anyone interested in helping urban refugee children and adolescents to shorten their length of formal schooling interruption in Thailand by providing their needed Thai language courses.

This present inquiry thus suggests the following words: what remains the core challenge for humanitarian based language learning programs at multiple urban refugee sites in Thailand is the balance that should be made between the 
necessary regular Thai language teaching, which is to end formal schooling interruption for urban refugee children and adolescents in decreasing their socio-economic inequalities, and the need to teach English language.

\section{REFERENCES}

[1] Adelman, H. (ed.) (1990). Refuge: Canada's periodical on refugees, 10 (2), pp. 1-20, Ontario, Canada: York University.

[2] Ellis, N. C. (ed.) (2010). CHAPTER 5: The policies and politics of educating refugee adolescents. Language Learning, 60, pp. 119-145. Ann Arbor, MI: University of Michigan.

[3] Huguet, J., \& Punpuing, S. (2005). International migration in Thailand [Electronic Version].Bangkok, Thailand: International Organization for Migration. Retrieved on Oct 13, 2010, from the Web Site: http://www.iom-seasia.org/resource/pdf/SituationReport.PDF

[4] Jesuit Refugee Service (n.d.). Urban refugee program, Bangkok. Retrieved December 18, 2010, from the Jesuit Refugee Service Web Site: http://jrs.or.th/thai/

[5] Settlement English (n.d.). ACL settlement English, York Street: Sydney. Retrieved November 11, 2011, from the Settlement English Web Site: http://www.acl.edu.au/

[6] UNHCR. (2006). The 1951 refugee convention: Questions \& answers [Brochure]. Geneva: Archives of the United Nations.

Hugo Yu-Hsiu Lee is a fellowship award-winning researcher at the Indiana University in 2007-2008. He holds a Ph.D. in language education from the Indiana University Bloomington, Indiana-USA. He has published scholarly articles and books internationally in Germany, USA, UK, Taiwan, and Thailand. He is currently teaching qualitative research methodology for doctoral students in the Graduate School of Language and Communication at the National Institute of Development Administration in Thailand. 